\title{
Isolation and characterization of Listeria monocytogenes among women attending Jimma University medical center, Southwest Ethiopia
}

\author{
Lencho Girma ${ }^{1}$, Alene Geteneh ${ }^{2 *}$, Demisew Amenu ${ }^{3}$ and Tesfaye Kassa ${ }^{4}$
}

\begin{abstract}
Background: Listeria monocytogenes (LM) has come to be a major public health issue of at-risk groups, causing high morbidity and mortality. Despite this data, studies are very limited in developing countries like Ethiopia. Thus, we aimed to isolate and characterize LM in terms of antibiogram and biofilm formation among pregnant women with fever, women with a history of spontaneous abortion, women with a history of fetal loss, and women with preterm delivery at Jimma University Medical Center (JUMC), southwest Ethiopia.

Methods: A cross-sectional study was done among 144 women from June to August 2019. Isolates were tested for antibiotic susceptibility and biofilm formation using disc diffusion and microtiter plate method, respectively. Data were collected using a structured questionnaire, entered into Epidata 3.1 and logistic regression was done by SPSS V25.0.

Results: LM was isolated in 8 (5.56\%) of 144 screened women. The isolation rate of LM was relatively higher among women with a history of fetal loss (9.7\%), followed by women with preterm delivery (6.25\%). One of the six cord blood was positive for $L M$, indicating that the transplacental transmission rate at JUMC was $16.7 \%$. More than $2 \%$ of women with an ongoing pregnancy were found to have LM septicemia, which could hurt their fetus. All of the isolates tested were susceptible to Ampicillin. However, all of the isolates were resistant to Penicillin and Meropenem and were biofilm producers.
\end{abstract}

Conclusions: The high magnitude of pregnancy-related listeriosis in the current study setting appears that implementation of educational programs targeting risk reduction and more studies to identify sources of LM are warranted. The choice of antibiotics should be after susceptibility testing.

Keywords: Women, Listeria monocytogenes, Antimicrobial susceptibility, Biofilm, Ethiopia

\section{Introduction}

Listeria monocytogenes (LM), a causative agent of listeriosis have emerged as an important foodborne illness of global concern $[1,2]$. It is a major public health problem for at-risk groups, causing high morbidity and mortality.

\footnotetext{
* Correspondence: aleneget@gmail.com

${ }^{2}$ Department of Medical Laboratory Science, College of Health Sciences, Woldia University, Woldia, Ethiopia

Full list of author information is available at the end of the article
}

Pregnant women had a 20-times more risk of developing listeriosis compared to the general population [3]. Studies indicated that LM is responsible for spontaneous abortion, stillbirth, and preterm delivery in pregnant women $[3,4]$. The infection can be transmitted from mother to growing fetus through placenta following maternal septicemia, or by the ingestion of amniotic fluid and passage through infected birth canal [5]. Invasive

C C The Author(s). 2021 Open Access This article is licensed under a Creative Commons Attribution 4.0 International License, which permits use, sharing, adaptation, distribution and reproduction in any medium or format, as long as you give appropriate credit to the original author(s) and the source, provide a link to the Creative Commons licence, and indicate if changes were made. The images or other third party material in this article are included in the article's Creative Commons licence, unless indicated otherwise in a credit line to the material. If material is not included in the article's Creative Commons licence and your intended use is not permitted by statutory regulation or exceeds the permitted use, you will need to obtain permission directly from the copyright holder. To view a copy of this licence, visit http://creativecommons.org/licenses/by/4.0/ The Creative Commons Public Domain Dedication waiver (http://creativecommons.org/publicdomain/zero/1.0/) applies to the data made available in this article, unless otherwise stated in a credit line to the data. 
listeriosis is usually associated with pregnant women, infants, neonates, organ transplant recipients, HIV, and cancer patients, and the clinical presentations of invasive listeriosis include septicemia, meningitis, meningoencephalitis, and gastroenteritis [6, 7].

The predilection of LM in the feto-maternal unit contributes to fatal outcomes in the fetus and/or mother. However, the exact mechanism often remains unexplained [8]. Listeriosis is usually treated by a combination of ampicillin and aminoglycoside $[9,10]$. However, LM isolates had shown variable responses to commonly prescribed antibiotics [11]. Studies on the magnitude and antimicrobial susceptibility pattern of human listeriosis are scarce in most African countries including Ethiopia. Thus, we aimed to isolate and characterize LM in terms of antibiogram and biofilm formation.

\section{Methods}

\section{Study setting}

A prospective cross-sectional study was conducted at JUMC from June 1, 2019, to August 30, 2019. JUMC is one of the teaching and referral hospitals in the South Western part of Ethiopia, providing different services for a catchment population of about 15 million people. JUMC has 659 beds out of which 52 beds in maternity and 60 beds in the gynecology and obstetrics ward. The medical center admits more than 20,000 patients and its yearly outpatient visits is more than 170,000 patient [12].

\section{Eligibility criteria}

Pregnant women with fever, women having spontaneous abortion, and women who had preterm delivery were included in the study. While pregnant women who were on antibiotics in the past 2 weeks before the study and women having safe abortion care were excluded from the study.

\section{Data collection and culture}

A total of 144 women who fulfill the inclusion criteria, and willing to participate in the study were recruited. Trained midwives conducted a face-to-face interview using the structured questionnaire, and collected maternal blood and cord blood specimens. There were 138 maternal blood and 6 cord blood samples collected from 144 women. 5 to $10 \mathrm{ml}$ of venous or cord blood was directly inoculated into $50 \mathrm{ml}$ of tryptic soy broth (difco, USA) with $0.6 \%$ yeast extract (TSBYE) (Oxoid, England) and incubated at $35^{\circ} \mathrm{C}$ for $24 \mathrm{~h}$. Subculture was made immediately after the first sight of growth noticed onto Listeria selective agar (LSA) medium (Himedia, India). The results were reported as negative if samples showed no evidence of growth on TSBYE for 7 days [13].

\section{Isolation of $L$. monocytogenes}

L. monocytogenes typically grows as a small yellow colony on LSA and grey to white beta-hemolytic colonies on $5 \%$ sheep blood agar (Himedia, India). Preliminary identification of LM was done by Gram staining, hemolysis pattern on 5\% sheep blood agar, and observation of its tumbling motility in a wet mount light microscopy after overnight incubation of typical colonies inoculated in TSBYE at $25^{\circ} \mathrm{C}$ and $37^{\circ} \mathrm{C}$. Furthermore, Catalase, Oxidase, CAMP factor test, and sugars fermentation (mannitol, maltose, dextrose, sucrose, lactose, and rhamnose) was performed for species identification and confirmation of LM [14-16].

\section{Antimicrobial susceptibility testing}

Three to five pure colonies of LM from overnight grown culture were suspended in sterile normal saline. The turbidity of suspension was checked against the $0.5 \mathrm{McF}$ arland standard. Antimicrobial susceptibility testing (AST) was performed by Kirby Bauer disk diffusion technique on Muller Hinton Agar (MHA) supplemented with fresh 5\% sheep blood (Himedia, India). Antibiotics tested include: Doxycycline $(30 \mu \mathrm{g})$, Penicillin G $(10 \mu \mathrm{g})$, Cotrimoxazole $(25 \mu \mathrm{g})$, Ampicillin $(10 \mu \mathrm{g})$, Erythromycin $(15 \mu \mathrm{g})$, Clindamycin $(2 \mu \mathrm{g})$, Ciprofloxacin $(5 \mu \mathrm{g})$, Gentamicin $(10 \mu \mathrm{g})$, Rifampicin $(5 \mu \mathrm{g})$ and Meropenem $(10 \mu \mathrm{g}))$. Suspended isolates were inoculated on MHA supplemented with $5 \%$ sheep blood, antibiotic discs placed firmly and incubated at $37^{\circ} \mathrm{C}$ for $24 \mathrm{~h}$. Zone of inhibition was measured and interpreted according to CLSI 2016 [17] and EUCAST guideline for LM [18].

\section{Detection of biofilm production}

Microtiter plate assay is the most frequently used method to determine biofilm production. The protocol used was adapted from Djordjevic et.al [19] and the result was interpreted as per [20].

\section{Statistical analysis}

Data were checked for completeness, coded, and entered into Epi-data version 3.1, and exported to SPSS v. 25.0 for analysis. Binary logistic regression was conducted for sociodemographic and clinical variables against LM positivity. Nonparametric correlation analysis was done for isolates against the number of antibiotics resistant and susceptible. $P$-value $<0.05$ was considered statistically significant.

\section{Quality assurance}

The prepared questionnaire was evaluated by obstetricians. $5 \%$ of the questionnaire was pretested at Shenan Gibe hospital, the nearby hospital in Jimma town. The training was provided for data collectors, and the collected data were checked for completeness in the field. LM (ATCC 19115) was used as the reference strain for Listeria monocytogenes. 


\section{Results}

\section{Socio-demographic characteristics}

A total of 144 women participated in this study. The mean age of women was $26.48 \pm 5.03$ years. The majority $(59 \%(85 / 144))$ of women were aged between 25 and 34 years old. More than $2 / 3$ rd of study participants had formal education, and $73.6 \%(n=106 / 144)$ of women were housewives (Table 1.). LM was isolated in $5.56 \%(8 / 144)$ of all study participants. Seven of the isolates were recovered from 138 maternal blood (5.07\%). One of the six cord blood (16.67\%) was positive, indicating the rate of transplacental transmission at JUMC.

\section{Clinical sign and symptoms}

Among the study participants, $44.4 \%(n=64))$ had preterm delivery, 34\% $(n=49)$ had ongoing pregnancy, and $21.6 \%(n=31))$ had a fetal loss. Fever $(n=100)$ and headache $(n=62)$ the most frequent symptoms noted. Of the 8 isolates, the majority were recovered from women with fever $(n=7)$ and headache $(n=5)$. More than $32 \%(n=$ 47 ) of women experienced bad obstetrics history (preterm delivery, stillbirth, and spontaneous abortion) in the past, at least once in their lifetime. Underlying medical conditions were also noted in pregnant women; HIV/AIDS $(n=5)$, chronic hepatitis $(n=4)$, hypertension $(n=3)$, and heart disease $(n=2)$. However, LM was not recovered in any of the women with underlying diseases. LM isolation rate was relatively higher (9.7\%) among women with fetal loss, and women with preterm delivery (6.25\%). None of the clinical characteristics were found correlated with LM recovery (Table 2.).

\section{Antimicrobial susceptibility of $L$. monocytogenes}

All of the isolates were shown resistant (100\%) for meropenem and penicillin. LM isolates also showed a relatively decreasing level of resistance to ciprofloxacin $(n=$ 6 , 75\%), cotrimoxazole or doxycycline $(n=4,50 \%)$, erythromycin or clindamycin $(n=3,37.5 \%)$, and gentamicin $(n=2,25 \%)$. Ampicillin was found the choice of antibiotics, susceptible to all isolates followed by gentamicin (75\%), rifampicin (62.5\%), erythromycin (62.5\%), and clindamycin (62.5\%) (Fig. 1).

\section{Biofilm production}

The microtiter plate assay showed that all the isolates were biofilm former. Isolates OD value was crosstabulated against the number of antibiotics (Table 3).

\section{Discussion}

Pregnancy-related listeriosis is an important public health concern of feto-maternal units due to the high morbidity and mortality to the fetus and or mother [8, 21 . In the current study, LM was isolated in $5.56 \%$ (8/ 144 ) of the study participants; which was in agreement with findings in Germany (3.3\%) [22], Colorado, USA (2.5\%) [23], and Indonesia (9\%) [13]. Similarly, our finding was in line with African studies; west Africa (4.6\%) [24], Nigeria (8.04\%) [25], and the previous study in Tigray, Ethiopia (8.5\%) [26]. These consistent findings could suggest the global importance of pregnancyassociated listeriosis irrespective nation's developmental status. On other hand, our finding was higher as compared to India (0.32\%) [27] and India (0.81\%) [28], and Tanzania (0.68\%) [29]. The discrepancy could be explained by the variation in the laboratory method used, population difference, and exposure variability.

Our isolates were completely resistant to meropenem and penicillin, followed by ciprofloxacin resistance (75\%) (Fig. 1.). The increased resistance to penicillin in this study was similar to the previous study in Tigray, Ethiopia [26]. This directs the essence of an antibiogram for on-time and accurate treatment of pregnant women and their fetuses, as penicillin is the drug of choice. Ampicillin was found the choice of antibiotics in our study, as do findings

Table 1 Bivariate analysis of socio-demographic characteristics among study participants at JUMC, June to August 30, 2019, southwest Ethiopia

\begin{tabular}{|c|c|c|c|c|c|c|}
\hline \multirow{2}{*}{\multicolumn{2}{|c|}{$\begin{array}{l}\text { Socio-demographic characteristics } \\
(n=144)\end{array}$}} & \multirow{3}{*}{$\begin{array}{l}\begin{array}{l}\text { Frequency } \\
\text { (\%) }\end{array} \\
45(31.3)\end{array}$} & \multicolumn{2}{|c|}{ L. monocytogenes } & \multirow{3}{*}{$\begin{array}{l}P \\
\text { value } \\
1\end{array}$} & \multirow[t]{3}{*}{$95 \% C . I^{a}$} \\
\hline & & & \multirow{2}{*}{$\begin{array}{l}\text { Yes (\%) } \\
1(2.2)\end{array}$} & \multirow{2}{*}{$\begin{array}{l}\text { No (\%) } \\
44(97.8)\end{array}$} & & \\
\hline Age of women & $18-24$ & & & & & \\
\hline & $25-34$ & $85(59.0)$ & $6(7.1)$ & 79 (92.9) & 0.4 & $3.385(0.198,57.931)$ \\
\hline & $35-45$ & $14(9.7)$ & $1(7.1)$ & $13(92.9)$ & 0.991 & $1.013(0.113,9.111)$ \\
\hline Residence & Urban & $93(64.6)$ & $5(5.4)$ & $88(94.6)$ & 0.899 & $1.1(0.252,4.803)$ \\
\hline & Rural & $51(35.4)$ & $3(5.9)$ & $48(94.1)$ & & \\
\hline Formal education & No & $48(33.3)$ & $2(4.2)$ & $46(95.8)$ & 0.609 & $1.533(0.298,7.899)$ \\
\hline & Yes & $96(66.7)$ & $6(6.2)$ & $90(93.8)$ & 1 & \\
\hline Occupation (Housewife) & Yes & $106(73.6)$ & 7 (6.6) & 99 (93.4) & 1 & \\
\hline & No & $38(26.4)$ & $1(2.6)$ & 37 (97.4) & 0.376 & $2.616(0.311,21.994)$ \\
\hline
\end{tabular}

${ }^{\mathrm{a} C . I . ~ s t a n d s ~ f o r ~ t h e ~ c o n f i d e n c e ~ i n t e r v a l ~}$ 
Table 2 Bivariate analysis of clinical characteristics and LM positivity from pregnant women at JUMC, June to August 30, 2019, southwest Ethiopia

\begin{tabular}{|c|c|c|c|c|c|}
\hline \multirow[t]{2}{*}{ Clinical variables $(n=144)$} & \multirow[t]{2}{*}{ No (\%) } & \multicolumn{2}{|c|}{ L. monocytogenes } & \multirow[t]{2}{*}{$P$-value } & \multirow[t]{2}{*}{$95 \%$ C.I. $^{a}$} \\
\hline & & Yes (\%) & No (\%) & & \\
\hline \multicolumn{6}{|l|}{ Clinical sign and symptoms } \\
\hline Fever & $100(69.4)$ & $7(7.0)$ & $93(93.0)$ & 0.279 & $0.309(0.037,2.590)$ \\
\hline Headache & $62(43.1)$ & $5(8.1)$ & $57(91.9)$ & 0.265 & $0.433(0.099,1.885)$ \\
\hline Gastroenteritis & $12(8.3)$ & $0(0)$ & $12(100)$ & 0.999 & 0.000 \\
\hline Vomiting & $15(10.4)$ & $0(0)$ & $15(100)$ & 0.999 & 0.000 \\
\hline \multicolumn{6}{|l|}{ Gestational age } \\
\hline$<28$ weeks & $28(19.4)$ & $1(3.6)$ & $27(96.4)$ & & 1 \\
\hline$\geq 28$ weeks & $116(80.6)$ & $7(6.0)$ & $109(94.0)$ & 0.614 & $0.577(0.068,4.888)$ \\
\hline had past "bad obstetrics history" & $47(32.6)$ & $4(8.5)$ & $93(91.5)$ & 0.291 & $0.462(0.110,1.936)$ \\
\hline No past "bad obstetrics history" & $97(67.4)$ & $4(4.1)$ & $43(95.9)$ & & 1 \\
\hline
\end{tabular}

${ }^{a}$ C.I. stands for the confidence interval

" " women with recurrent spontaneous abortions, history of fetal loss or history of preterm delivery

in India [28], Poland [30] Iran [31], and Brazil [9]. The resistance to penicillin (100\%), cotrimoxazole (50\%), and gentamicin (25\%) in the current study (Fig. 1.) were higher compared to $28.6 \%$ resistance to penicillin and no resistance to cotrimoxazole and gentamicin reported in India [32]. The above findings presented the emergence of antibiotic-resistant strains with a varying degree of resistance $[11,26,31,32]$. These could show the potential threat to public health by antibiotic resistance LM strains and implicates the need for AST before any antibiotic administration to pregnancy-associated listeriosis.
This study noted that all of the isolates were biofilm producers, which was in agreement with the study in Poland [30]. The biofilm production might offer an opportunity to persist on food processing devices and medical devices like catheters and devices related to delivery [30] increase the risk of getting infected [33]. Our study also investigated that the biofilm production capacity of LM was found not associated with drug resistance. However, the higher resistance to penicillin, meropenem, and ciprofloxacin might be connected with biofilm formation [34].

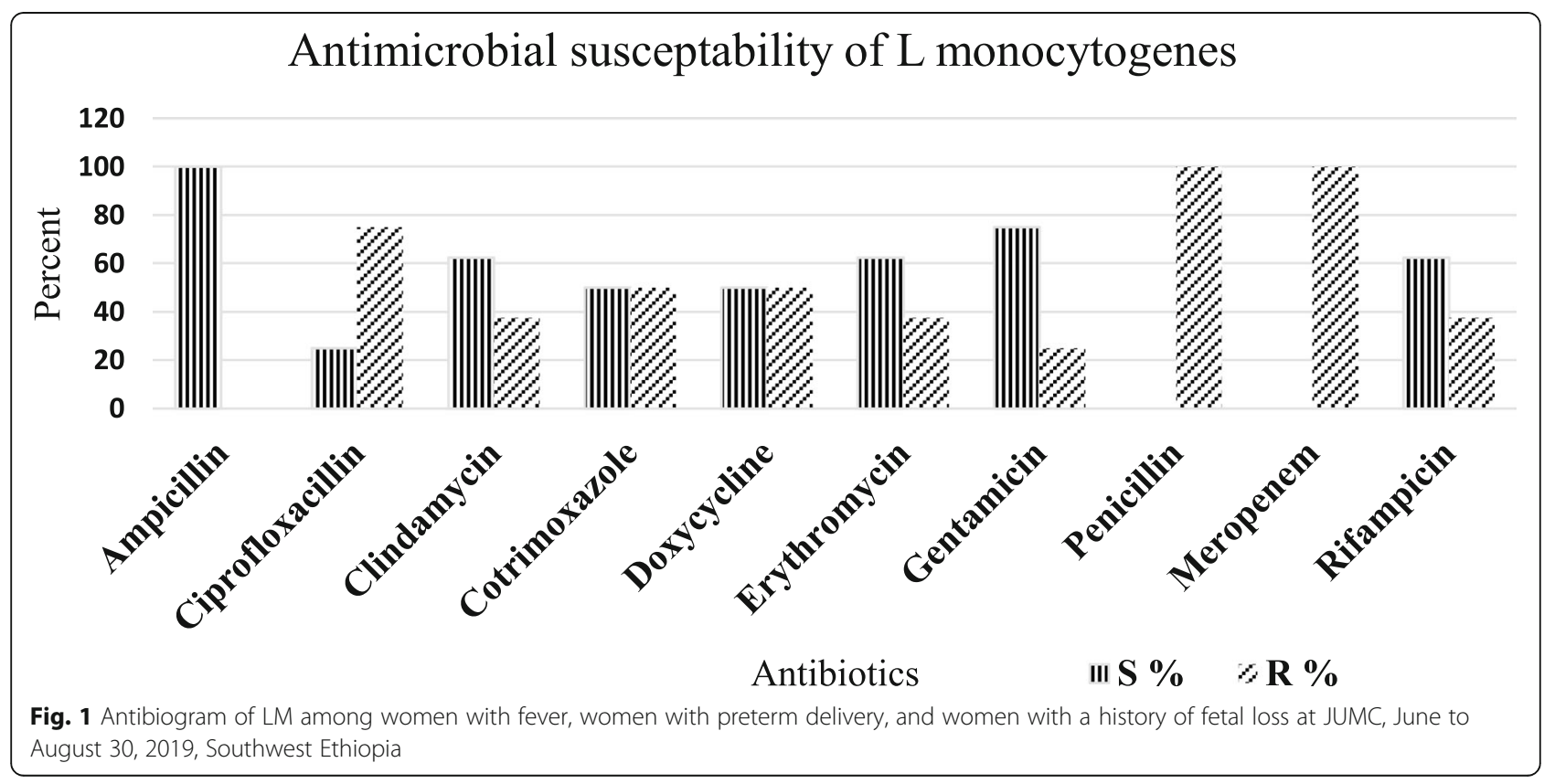


Table 3 OD value of isolates with the number of antibiotics susceptible and resistant

\begin{tabular}{llll}
\hline Isolate & $\begin{array}{l}\text { OD of } \\
\text { Isolates }\end{array}$ & No of antibiotics \\
\cline { 3 - 4 } & 0.0926 & 7 & Susceptible \\
\hline Isolate 1 & 0.1270 & 5 & 3 \\
Isolate 2 & 0.0705 & 3 & 5 \\
Isolate 3 & 0.0895 & 5 & 7 \\
Isolate 4 & 0.0646 & 5 & 5 \\
Isolate 5 & 0.1702 & 4 & 5 \\
Isolate 6 & 0.2081 & 3 & 6 \\
Isolate 7 & 0.3857 & 2 & 7 \\
Isolate 8 & & 5 & 8 \\
\hline
\end{tabular}

The Spearman correlation analysis of OD value of biofilm assay and the number of antibiotic-resistant for LM showed an insignificant association $(p>0.05)$.

We isolated and characterized LM in terms of antibiogram and biofilm formability among pregnant women with fever, women with preterm delivery, and women with a history of fetal loss at JUMC, Ethiopia for the first time. Due to the nature of the study, we were limited to include asymptomatic pregnant women and other athigh risk groups. We were also unable to assess molecular grounds why isolates were ampicillin susceptible but resistant to penicillin and carbapenem due to limited resources. The high prevalence of pregnancy-related listeriosis in the current study setting appears that implementation of educational programs targeting risk reduction and more studies to identify sources of LM are warranted. Increased resistance of LM to penicillin, meropenem, ciprofloxacin, cotrimoxazole, and doxycycline; indicated that the choice of antibiotics should be after antimicrobial susceptibility testing.

\section{Acknowledgments}

The authors are grateful to Jimma University School of medical laboratory for granting permission to use the research laboratory. We also wish to express our gratitude to the study participants for their willingness to take part in the study. Our appreciation also goes to Mr. Bikila and Mr. Negese for their unwavering commitment to collecting clinical samples and data from study participants. Also, our special thanks go to Mizan Aman Health Science College for providing the fund for this study.

\section{Authors' contributions}

A.G conceived and designed the study, and wrote the manuscript, L. G designed the study, conducted laboratory investigation, analyzed the data, D. A study participant selection, and supervision, T. K provide materials, supervised laboratory work, and all the investigation process. All authors read and approved the final manuscript.

\section{Funding}

This study was funded by Jimma University and Mizan Aman, College of Health Sciences.

\section{Availability of data and materials}

The datasets used or analyzed during the current study are available from the corresponding author on reasonable request.

\section{Declarations}

\section{Ethics approval and consent to participate}

Ethical clearance was obtained from Jimma University IRB with reference number: IHRPGD/563/2018. Informed written consent was obtained from each study participant, and in case of participants having no formal education, informed consent was obtained from their legal guardians. Lab finding was disclosed to the study participant and their health care provider. Helsinki declarations were used as guiding principles during this research activity.

\section{Consent for publication \\ Not applicable.}

\section{Competing interests}

The authors declared that no competing interests.

\section{Author details}

${ }^{1}$ Department of Medical Laboratory Science, Mizan Aman College of Health Sciences, Aman, Ethiopia. ${ }^{2}$ Department of Medical Laboratory Science, College of Health Sciences, Woldia University, Woldia, Ethiopia. ${ }^{3}$ Department of Obstetrics and Gynecology, School of Medicine, Jimma University, Jimma, Ethiopia. ${ }^{4}$ School of Medical Laboratory Sciences, Jimma University, Jimma, Ethiopia.

Received: 15 January 2021 Accepted: 26 May 2021

Published online: 12 June 2021

\section{References}

1. Mateus T, Silva J, Maia RL, Teixeira P. Listeriosis during pregnancy: a public health concern. ISRN Obstet Gynecol. 2013;2013:1-6. https://doi.org/10.11 55/2013/851712.

2. World Health Organization (WHO). WHO estimates of the global burden of foodborne diseases: foodborne disease burden epidemiology reference group 2007-2015. Geneva, Switzerland; 2015.

3. Baud D, Greub G. Intracellular bacteria and adverse pregnancy outcomes. Clin Microbiol Infect. 2011;17(9):1312-22. https://doi.org/10.1111/j.14690691.2011.03604.x

4. EFSA. The European Union summary report on trends and sources of zoonoses, zoonotic agents and food-borne outbreaks in 2013: European Food Safety Authority; 2015.

5. Amene $Y$, Firesbhat A. Listeriosis in large ruminants: a review. Acad J Animal Dis. 2016;5:16-21.

6. Institute of Obstetricians and Gynaecologists. Clinical Practice Guideline Listeriosis in pregnancy. Ireland: Royal College of Physicians of Ireland; 2018.

7. Communicable Diseases Network Australia (CDNA). Listeriosis. CDNA National Guidelines for Public Health Units. 2018.

8. Allerberger F, Wagner M. Listeriosis: a resurgent foodborne infection. Clin Microbiol Infect. 2010;16(1):16-23. https://doi.org/10.1111/j.1469-0691.2009. 03109.x.

9. Lemes-Marques EG, Cruz CD, Destro MT. Pheno- and genotypic characterization of Listeria monocytogenes clinical isolates from the southwestern region of the state of Sao Paulo, Brazil. Braz J Microbiol. 2007; 38(2):287-92. https://doi.org/10.1590/S1517-83822007000200019.

10. Lamont RF, Sobel J, Mazaki-Tovi S, Kusanovic JP, Vaisbuch E, Kim SK, et al. Listeriosis in human pregnancy: a systematic review. J Perinat Med. 2011; 39(3):227-36. https://doi.org/10.1515/jpm.2011.035.

11. Kuch A, Goc A, Belkiewicz K, et al. Molecular diversity and antimicrobial susceptibility of Listeria monocytogenes isolates from invasive infections in Poland (1997-2013). Sci Rep. 2018;8(1):1-11.

12. Jimma University Medical Center. Jimma University Medical Center governing Board reviewed 2010 E.C. Performance and approved 2011 E.C. plan. Jimma University; 2018.

13. Silaen M, Yerizel E, Syukur S, et al. The prevalence of Listeria monocytogenes in placental tissue from abortion and fetal death at mother and Child's Sri Ratu hospital, Medan, Indonesia. Am Sci Res J Eng Technol Sci (ASRJETS). 2017;33(1):207-16.

14. Benetti TM, Monteiro CLB, Beux MR, Abrahão WM. Comparison of selective agars recommended by method ISO 11290-1 and chromogenic agars for the isolation of Listeria species in refrigerated sausages. Brazilian J Pharm Sci. 2012;48(4):677-81. https://doi.org/10.1590/S1984-82502012000400011. 
15. Huang SL, Chou YT, Hsieh YC, Huang YC, Lin TY, Chiu CH. Epidemiology and clinical characteristics of Listeria monocytogenes bacteremia in a Taiwanese medical center. J Microbiol Immunol Infect. 2010;43(6):485-90. https://doi.org/10.1016/S1684-1182(10)60075-8.

16. Alexandre L, Thomas H, Anna O, et al. Listeria monocytogenes. Princ Pract Pediatr Infect Dis. 2018;1:781-5.

17. CLSI, editor. Methods for antimicrobial dilution and disk susceptibility testing of infrequently isolated or fastidious Bacteria. 3rd ed CLSI guideline M45. Wayne: Clinical and Laboratory Standards Institute; 2016.

18. Testing ECOAS. Breakpoint tables for interpretation of MICs and zone diameters. 2018, version 8.0. 2018

19. Djordjevic D, Wiedmann M, CLandsborough L. Microtiter plate assay for assessment of Listeria monocytogenes biofilm formation. Appl Environ Microbiol. 2002;68(6):2950-8. https://doi.org/10.1128/AEM.68.6.2950-2958.2002.

20. Henriques A, Fraqueza M. Biofilm-forming ability and biocide susceptibility of Listeria monocytogenes strains isolated from the ready-to-eat meatbased food products food chain. LWT-Food Sci Technol. 2017;81:180-7. https://doi.org/10.1016/j.lwt.2017.03.045.

21. Filipello V, Amato E, Gori M, Huedo P, Ciceri G, Lomonaco S, et al. Epidemiology and molecular typing of pregnancy-associated listeriosis cases in Lombardy, Italy, over a 10-year period (2005-2014). Infect Dis Obstet Gynecol. 2017;2017:1-8. https://doi.org/10.1155/2017/6479121.

22. Kaur S, Malik SV, Vaidya VM, et al. Listeria monocytogenes in spontaneous abortions in humans and its detection by multiplex PCR. J Appl Microbiol. 2007;103(5):1889-96. https://doi.org/10.1111/j.1365-2672.2007.03414.x.

23. Imanishi M, Routh JA, Klaber M, Gu W, Vanselow MS, Jackson KA, et al. Estimating the attack rate of pregnancy-associated listeriosis during a large outbreak. Infect Dis Obstet Gynecol. 2015;2015:1-5. https://doi.org/10.1155/2 015/201479

24. Fall NS, Sarr M, Diagne N, Bassène H, Sokhna C, Lagier JC, et al. Listeria monocytogenes detected in vaginal self-samples of 2 women after spontaneous miscarriage, Senegal, West Africa. Eur J Clin Microbiol Infect Dis. 2020;39(2):393-4. https://doi.org/10.1007/s10096-019-03739-0.

25. Shindang J, Shindang CO, Ekwempu Al. Incidence of Listeria monocytogenes and other Bacteria in spontaneous abortion cases in Jos. Nigerian J Biotechnol. 2013;25(2013):18-22.

26. Welekidan LN, Bahta YW, Teklehaimanot MG, et al. Prevalence and drug resistance pattern of Listeria monocytogenes among pregnant women in Tigray region, northern Ethiopia: a cross-sectional study. BMC Res Notes. 2019;12(1):1-6.

27. Dhanashreea B, Ottab SK, Karunasagarb I, et al. Incidence of Listeria species in clinical and food samples in Mangalore, India. Food Microbiol. 2003;20(4): 447-53. https://doi.org/10.1016/S0740-0020(02)00140-5.

28. Soni DK, Singh DV, Dubey SK. Pregnancy - associated human listeriosis: virulence and genotypic analysis of Listeria monocytogenes from clinical samples. J Microbiol. 2015;53(9):653-60. https://doi.org/10.1007/s12275-0155243-9.

29. Ernest Al, Ng'Walida N, Ndaboine $\mathrm{E}$, et al. Maternal vaginorectal colonization by group $B$ Streptococcus and Listeria monocytogenes and its risk factors among pregnant women attending tertiary hospital in Mwanza, Tanzania. Tanzania J Health Res. 2015;17(2):1-9.

30. Skowron K, Brożek K, Łukasik M, Wiktorczyk N, Korkus J, GospodarekKomkowska E. Assessment of drug susceptibility and biofilm formation ability by clinical strains of Listeria monocytogenes. Disaster Emerg Med J. 2020;5(1):12-8. https://doi.org/10.5603/DEMJ.a2020.0002.

31. Heidarzadeh S, Pourmand MR, Hasanvand S, et al. Antimicrobial Susceptibility, Serotyping, and Molecular Characterization of Antibiotic Resistance Genes in Listeria monocytogenes Isolated from Pregnant Women with a History of Abortion. Iran J Public Health. 2021:1:1.

32. Babu G, Balamuruganvelu S, Maulingkar S, et al. Incidence rate and antibiotic susceptibility pattern of Listeria Species in high risk groups. Natl J Lab Med. 2017;6(2):1-5.

33. Doijad S, Barbuddhe S, Garg S, et al. Biofilm-forming abilities of Listeria monocytogenes serotypes isolated from different sources. PLoS One. 2015; 10(9):e0137046. https://doi.org/10.1371/journal.pone.0137046.

34. Tasneem U, Yasin N, Nisa I, et al. Biofilm producing bacteria: A serious threat to public health in developing countries. J Food Sci Nutr. 2018;1 (2):25-31.

\section{Publisher's Note}

Springer Nature remains neutral with regard to jurisdictional claims in published maps and institutional affiliations.

\section{Ready to submit your research? Choose BMC and benefit from:}

- fast, convenient online submission

- thorough peer review by experienced researchers in your field

- rapid publication on acceptance

- support for research data, including large and complex data types

- gold Open Access which fosters wider collaboration and increased citations

- maximum visibility for your research: over $100 \mathrm{M}$ website views per year

At $\mathrm{BMC}$, research is always in progress.

Learn more biomedcentral.com/submissions 